\title{
ITALIA: ANATOMÍA DE UNA CRISIS
}

\section{Santiago Gamboa}

Resumen: Mario y su primo Angelino - filofascista, el primero; comunista, el segundo- son dos ancianos de provincia con opiniones divergentes sobre la crisis económica y moral que vive Italia. Pese a todo ambos son inseparables. Mauro Sari es un microempresario de 47 años que se suicida prendiéndose fuego al interior de su auto, en un aparcadero solitario. Antes había visitado a Beppe Grillo buscando ayuda.

A través de una serie de historias humanas tomadas de recortes de prensa, de su propia experiencia personal y del mundo empresarial y editorial italiano, el escritor y diplomático colombiano Santiago Gamboa muestra no sólo las distintas percepciones sobre la crisis, sino también la manera en que ésta ha golpeado a la sociedad italiana, cómo la enfrentan la crisis algunos sectores y cuáles son algunas de sus secuelas

Santiago Gamboa. Escritor colombiano. Estudió literatura en la Universidad Javeriana de Bogotá, y literatura cubana en la Universidad de la Sorbona, París. Licenciado en filología hispánica en la Universidad Complutense, Madrid. Fue corresponsal del periódico El Tiempo en París, columnista y colaborador de varias revistas. Autor, además de cuentos y relatos de viajes, de las novelas Páginas de Vuelta (1995), Perder es Cuestión de Método (1997), Los Impostores (2001), El Síndrome de Ulises (2005), Hotel Pekin (2008) y Necrópolis (2009). Fue miembro de la delegación de Colombia en la Unesco y de la embajada colombiana en la India. Actualmente vive en Italia. Dirección electrónica: sangamboa@gmail.com. 
más visibles. A la pregunta de qué hacer ahora, luego de que las medidas de austeridad impulsadas por Monti no resultaran eficaces, Gamboa sugiere que tal vez Angellino, el viejo comunista de Collelungo, tenga razón: “'Hay que hacer una cura de pobreza' y esperar que la vieja Italia, que según su constitución es una 'República fundada sobre el trabajo', vuelva a salir a flote por la fuerza de su historia y de su talento individual".

Palabras clave: Italia, crisis.

Recibido y aceptado: junio de 2013.

\section{ITALY: THE ANATOMY OF A CRISIS}

Abstract: Mario and his cousin Angelino - the first a phylofascist, the latter a communist-are two provincial old men with differing opinions on the economic and moral crisis now prevalent in Italy. Despite everything, they are inseparable.

Mauro Sari is a 47-year-old micro-entrepreneur who commits suicide by setting himself on fire inside his car in a solitary parking lot. He had visited Beppe Grillo earlier seeking help. Through a series of human stories taken from press clippings, from his own personal experience and from the Italian business and editorial world, Colombian writer and diplomat Santiago Gamboa shows not only the different perceptions of the crisis, but also the way in which the crisis has impacted Italian society, how some sectors are confronting it, and what some of its most visible consequences are. Gamboa suggests, in answer to the question of what to do now since the austerity measures pushed for by Monti did not prove to be effective, that perhaps Angelino, the old communist from Collelungo, is right: "Italians may have to endure poverty' and wait till the old Italy -a 'Republic founded on work,' as it Constitution says - rises again by the force of its history and individual talent."

Keywords: Italy, crisis.

Received and accepted: June 2013. 
ómo dice?, ¿qué ahora somos pobres?, eso son pamplinas", grita Mario Bove, enfurecido, sobre el mostrador de su bar, bebiendo una copa de sambuca, y agrega, " $i$ eso es cosa de los alemanes, que nos quieren robar el país!". Bove es famoso en el pueblo. Tiene 87 años y un lema: "Para vivir mucho hay que ser feliz, y para ser feliz se necesitan tres mujeres". El pueblo en cuestión se llama Collelungo y queda en la provincia de Rieti. Es pequeño, sobre una colina. Tiene 205 habitantes y casi todos son parientes. Hacen el mejor aceite de oliva de Italia.

"¡Es culpa de los alemanes, porque los alemanes de hoy no son como los de antes!", dice. Durante la guerra, un grupo de soldados del Tercer Reich vino a instalarse a su casa y convivieron con su familia. De ahí la admiración que Bove les tiene: "Eran gente buena, nos ayudaron", recuerda, "los americanos, en cambio, bombardearon Roma". Bove también es famoso por haber sido doble de Gregory Peck en un par de películas filmadas en Italia. Pero para él, hoy las cosas son diferentes. "Los alemanes decidieron darle un golpe a Italia para frenarla, es como en el boxeo, un directo a las costillas para sacarle el aire, y por eso nos pusieron a Monti".

Es lo mismo que lleva diciendo Silvio Berlusconi desde principios de año: que la crisis italiana es culpa de los alemanes por abandonar a la banca italiana cerrando el crédito y exigiendo ajustes fiscales y de gasto público, y que para eso Alemania y su gran Lucifer, Angela Merkel, propiciaron el nombramiento de Mario Monti, el gobierno "técnico" que debía entrar cual cirujano a tomar las medidas para que Italia funcionara de acuerdo al interés alemán. Esto lo dice Berlusconi por televisión y radio sin dar cifras ni explicaciones, no las necesita. Basta que lo diga para que la gente le crea, y entre menos cifras o ejemplos, mejor. Basta una frase sencilla: "Son los alemanes". Y quien dice Alemania, dice Europa.

"Son los alemanes", dice Bove, "quieren comprar barato en Italia, comprar nuestras tierras y casas y villas en el mar y viñedos, y por eso nos hunden, y sólo Berlusconi puede defendernos". En el campo, en miles de bares perdidos de pueblos de Italia, los clientes repiten estas frases. Berlusconi las dice para ellos. Es la gente sencilla, los campesinos que son de derecha con la misma parsimonia con que antes sus padres fueron fascistas. Muchos tienen la figura de Mussolini en la 
pantalla de su celular. Son fascistas porque sus padres fueron fascistas y porque alguna vez, durante la República de Salò, obtuvieron una casa del Estado a bajo precio y mejoraron en su trabajo. "No somos pobres, Italia siempre ha sido un país rico!", concluye Bove, y todos los que están con él lo miran y asienten en silencio, y siguen viendo el noticiero en el pequeño televisor pegado a la pared, a la izquierda del mostrador, a la espera de las actualidades deportivas.

El primo de Mario Bove se llama Angelino y está sentado en las sillas de afuera, para poder fumar. No le interesa el deporte. Es menor que Bove, tiene 83 años. Es comunista. A los once, cuando los americanos bombardearon la estación de trenes de Termini, en Roma, Angelino fue a pie desde el barrio de San Lorenzo para auxiliar a su padre. Alguien vino a decirle que estaba herido, debajo de una locomotora, y allá lo encontró, con esquirlas en una pierna y la rodilla pulverizada. Debió traerlo alzado hasta la casa. Su padre era del sindicato ferroviario y por eso Angelino es y sigue siendo comunista. Su aspecto es el de un viejo dandy algo venido a menos, con un pañuelo que podría ser de seda alrededor del cuello y gafas de lentes ahumados. "Mira los campos", me dice, "están casi vacíos, no hay trabajo". Es verdad. Antes se veía a mucha gente de otras partes, de Rumania y Yugoslavia sobre todo, empleándose en labores agrícolas, pero eso ha disminuido. Muchas de las microempresas han bajado su producción a mínimos, para reducir costos, y otras han quebrado.

"Esta crisis es una lucha de fuertes contra débiles", dice Angelino, "el banco ya no le da crédito al pequeño empresario porque gana más poniéndolo en bonos, ¿y sabes por qué?, porque las ayudas que el Estado les ha dado a los bancos, con la plata de los italianos, hace que sea más rentable para ellos seguir en crisis, ¿lo ves?", dice, y mientras habla hace un círculo con el dedo en el aire, y entonces pienso en preguntarle por qué lo sabe, cuáles son sus fuentes de información, un comunista italiano de 83 años, pero prefiero no decir nada, le he visto en el carro Il Manifesto, el periódico del Partido, y es muy posible que sea de ahí y de algunas emisoras radiales que extrae sus ideas, puede incluso que de algún programa de televisión, en el fondo es igual. Entonces le pregunto, ¿y en qué otras cosas ves la crisis?, y él responde, "bueno, es bastante obvio, mira los pueblos alrededor de Roma", dice, "se están volviendo a llenar con gente de la ciudad que no logra pagar los alquile- 
res de allá, y eso que han bajado. Al menos traerá de bueno que alguno de estos pueblos muertos, llenos de viejos, pueda resucitar".

Pueblos agónicos que ven llegar nuevos vecinos, familias, a veces con hijos pequeños. En Collelungo un apartamento de cien metros, con dos cuartos, salón y cocina, puede costar 300 euros al mes. La tercera parte que en Roma. El abono al bus, para ir todos los días, cuesta 75 euros mensuales. Son 56 kilómetros que a las seis de la mañana se hacen en hora y media. Además la familia está en el campo y no en una barriada de Roma al estilo de Tor Bella Monaca, o peor aún, Il Corviale, con ese edificio que le dicen Il Serpentone, que mide como un kilómetro y que es un gigantesco mall de drogas duras y recreativas. El campo conviene, claro que sí, porque todo es más barato: los servicios, la comida. Mejor que los hijos sean muchachos de provincia y no candidatos al presidio y a las curas de desintoxicación.

Mucho mejor.

"Los he visto llegar", me dice Angelino, "y eso es bueno para todos, porque las crisis, ¿sabes?, hay que saberlas vivir, te lo digo yo, que viví la posguerra con un pantalón, una camisa y unos zapatos remendados, y es que lo que a estos jóvenes de hoy les falta, además de trabajo, es una cura de pobreza en el cerebro, dejar de ser tan exquisitos, dejarse de tantos celulares y carros y marcas de calzoncillos y tonterías, y así aprenderán la vida, porque este país lo construyó gente sencilla y trabajadora, los Berlusconi y compañía fueron las hienas que llegaron después a aprovecharse y apropiarse de esa riqueza", dice, cada vez más agitado, encendiendo el tercer cigarrillo en línea, "y por eso ahora lo primero que tiene que cambiar es esa psicología, ese sistema de valores que Berlusconi le inyectó a esta sociedad para volverla sonriente y tonta, porque sólo puede ser tonto o cínico uno que siempre está haciendo chistes y riéndose, ¿no?”, y agrega, “es como lo del fútbol, y que no me oigan aquellos", dice y señala el interior del bar, "todo ese rollo de los fichajes y los millones de euros que ganan, imagínate, eso les quema las neuronas no sólo a los futbolistas sino sobre todo a los jóvenes que siguen con pasión esa estupidez, y es otra de las herencias de Berlusconi, haber convertido el deporte nacional en un juego de mafias, con millones de euros de por medio, todo ese derroche en un país empobrecido, y la gente en lugar de escupir y mirar para otro lado, exigiendo respeto, lo sigue y grita y mira el televisor como si fuera un milagro en directo, en fin, es como para ponerse a llorar", dice. 
De repente un ruido lo interrumpe, se abre la puerta del bar y sale Mario Bove. Le dice, "vamos". Angelino se levanta y los dos suben a una camioneta. En Roma tienen apartamentos separados, pero en el campo comparten una vieja casa. Son inseparables. En invierno, para ahorrar calefacción, duermen en la misma cama.

\section{II.}

Toda crisis es, sobre todo, una gran contradicción: educar muy bien a la juventud, esmerarse en darle contenidos, tecnología, experiencia, mundo, todo gratuitamente por parte del Estado, para luego depositarlos de forma abrupta en la calle, donde el desempleo es la ley de gravedad que los hace caer al abismo. No a todos, claro, sólo a una tercera parte. Los datos son escalofriantes: el 33,9\% de los menores de 25. Uno de cada tres. Y la contradicción, que es como una fosa que se agranda, va aún más lejos, pues además de todo estos jóvenes "son italianos". ¿Y esto qué quiere decir? Algo muy sencillo: que les gusta vestirse bien, con ropa de marca, les gusta que su celular sea $3 \mathrm{G}$ y su carro o moto nueva y sus calzoncillos Abercrombie o Victoria's Secret, les gusta ir al gimnasio que está de moda para tonificar los músculos y templar la barriga, reforzar el busto o los pectorales - en Italia es casi peor ser gordo que estar desempleado-, y no es fácil dejar estas costumbres, sería como cambiar el ADN de varias generaciones, hijas de la publicidad y el culto al refinamiento y a la moda propios de un país en el que todo lo visible es bello: las ciudades, el cielo, las montañas, los ríos y valles, las costas, el mar. Sin hablar del arte o la música.

Por eso el grado de malestar generado por la crisis, el desempleo y la pérdida gradual de la capacidad de consumo, es vivida en Italia como algo dramático. Los jóvenes sobreviven en las casas paternas pero suponen un peso muerto en la canoa familiar, a la que ya le entra el agua, pues la clase media lleva retrocediendo desde hace al menos cinco años, y de un modo muy visible. Conad, el supermercado que está a unas cuadras de mi casa, en Roma, prácticamente sólo vende las cosas que están en oferta, generalmente productos sin marca y con etiqueta del propio supermercado, es decir comprados al por mayor y empacados por ellos, que son lo más barato que hay en sus estanterías. Esto, por supuesto, estrangula lentamente a los mini mercados de la avenida Santa Costanza, al pequeño comerciante de jamones y quesos, cuyos 
precios no pueden competir con los de las grandes superficies. Así, el mini mercado de Piazza Istria vio bajar tanto su facturado que a los pocos meses debió despedir a dos de sus cuatro empleados — uno de ellos rumano-, reduciéndose al propietario y a su esposa, y eventualmente al hijo desempleado, que empezará su carrera de "trabajador precario".

Muchos — no sólo jóvenes - se han resignado a algo impensable hace una década: ya no buscar trabajo, sino horas de trabajo. Contratos limitados, sólo para algunos días difíciles de la semana, como el viernes y el sábado, que es cuando la gente más compra o más servicios requiere. Trabajos precarios, sin seguros ni prestaciones sociales, una situación en la que están hoy casi nueve millones de personas.

La otra solución para los jóvenes es emigrar. A Alemania, a Inglaterra. Sobre todo a Berlín, que es el nuevo destino soñado de los jóvenes europeos, pero que de todos modos tiene el problema del idioma, para el que pocos se prepararon. Varios hijos de amigos están en Berlín y dicen que la comunidad de italianos que busca trabajo allá es enorme, que sobreviven con ayudas familiares y a veces del Estado y que los que trabajan, por ahora, han encontrado empleos de baja formación y remuneración, como es el caso de los Call Centers. Son las nuevas rutas de la emigración: jóvenes italianos con títulos universitarios trabajando 9 horas diarias con un audífono en la cabeza y respondiendo llamadas, quejas de usuarios, activando o desactivando tarjetas electrónicas. Italia siempre ha sido país de migrantes, y ahora, en la segunda década del $\mathrm{XXI}$, vuelve a serlo como lo fue hace un siglo.

\section{III.}

Algunos amigos han pensado que vender sus casas les dará un respiro: podrán saldar lo que les queda de hipotecas bancarias, ponerse al día con impagos de impuestos y seguir adelante con un pequeño capital. Es el caso de Aquilino M., uno de mis vecinos en Roma. De acuerdo a las cifras tradicionales de valorización, su apartamento de 135 metros en la zona de Corso Trieste está en torno a los 800.000 euros, y ese es precisamente el precio que la agencia inmobiliaria Tecnocasa le puso a la propiedad el año pasado, en el 2012, antes de lanzarla al mercado. Pasaron las semanas y vinieron algunos posibles clientes interesados en la zona, pues Corso Trieste tiene fama de ser tranquilo, bien comunicado y de cierta reputación. Las visitas continuaron, pero 
sin ninguna oferta. Pasaron siete meses y, por fin, alguien se interesó y propuso pagar... ¡470.000 euros! Como es lógico mi vecino ni siquiera la consideró y le pidió a la agencia ser más profesional y selectiva, pero la respuesta fue demoledora: no se trata de "la mejor oferta" que hemos recibido, es simplemente la única.

Caminando por el barrio uno comprueba que Aquilino no fue el único que tuvo esa idea y que en casi todos los portones hay avisos de Se Vende y Se Arrienda. A partir de ahí mi vecino habló con varios porteros de la vecindad y todos dijeron que en sus edificios había uno, dos, cinco apartamentos en venta, pero que los dueños no querían poner avisos a la calle para no remover las aguas, pues saben que eso hace bajar el precio. Al final mi vecino llamó a la inmobiliaria para retirar su apartamento de la venta, pues con un $40 \%$ menos del valor inicial ya no le alcanzaba para sus planes iniciales, y entonces prefirió esperar.

Otro caso: el de un escritor italiano muy reconocido y talentoso al que llamaremos B., quien tiene una extraordinaria casa de campo en Liguria, con vista al Golfo de Génova y a las Cinque Terre. Como el mundo literario italiano no es ajeno a la crisis, B. debió regresar a Milán a hacer varios trabajos "alimenticios", así que decidió con su mujer poner la casa en venta. Pero les fue aún peor que a mi vecino de Roma, pues en tres años han tenido una sola visita y ninguna oferta. De un precio inicial de un millón y medio de euros las agencias le recomiendan bajarlo a la mitad. Nadie compra, nadie vende.

$Y$ ya que estamos con un escritor italiano, vale la pena mencionar que el pasado Salón Internacional del Libro de Turín - cuyo país invitado fue Chile - fue un termómetro bastante fidedigno de la crisis en el sector. Se debe tener en cuenta que Italia ha sido siempre un país en el que las empresas editoriales, tanto periodísticas como de libros en general, han sido tradicionalmente un buen negocio. Berlusconi creció en este mundo y luego dio el salto a la televisión, pero aún hoy continúa siendo dueño de prestigiosas casas editoras como el gigante Mondadori, así como de muchas revistas.

Pues bien, el balance de Turín, en términos del sector, fue devastador: a pesar de que hubo mucho público y las ventas durante el Salón fueron altas, las editoriales llegaron, prácticamente todas, a dar partes de derrota: descenso drástico en las ventas globales, despidos, límite a las publicaciones en lengua original y por supuesto a las traducciones contratadas. Y lo peor: despidos en todos los planteles. Feltrinelli, Mon- 
dadori, Einaudi, Rizzoli, los nombres más sonoros del mundo editorial italiano reduciendo personal, reduciendo publicaciones, reduciendo por supuesto los adelantos que dan a sus autores y reduciendo los pagos a los traductores. A pesar de que el eBook y en general el libro "on line" creció algún dígito, su incidencia en el mercado es muy pequeña, no llega al 5\% de las ventas de libros, pero en cambio sí ha contaminado el negocio del libro en papel, el cual cae y cae ya sin posible salvación.

$\mathrm{Si}$ antes los editores italianos tenían detectados a dos millones de italianos que compraban cuatro libros al mes —en el área literatura y ensayo-, lo que equivalía a un mercado superior al de toda la lengua española, hoy este grupo se ha reducido a una cuarta parte. De ahí que sólo los escritores italianos más célebres puedan vivir hoy correctamente de sus derechos de autor, caso de Roberto Saviano - que, en Italia, más que un escritor a secas es toda una figura mediática, casi una marca-, Umberto Eco, Andrea Camilleri, Alessandro Baricco y pocos más, y aquí me refiero sólo a los que considero verdaderos escritores, pues como pasa en todos los países también en Italia hay una producción de best-sellers locales con temas históricos o eróticos o con libros hechos por famosos del espectáculo que se han ido imponiendo en el lánguido mercado y que arrinconan aún más, con sus libros, a los verdaderos escritores. En suma: al mundo del libro lo aqueja la propia crisis del sector, más la crisis global del país. En suma: la crisis dentro de la crisis, y el resultado es que las ventas de los libros caen irremediablemente.

\section{IV.}

Como en las obras de Shakespeare, cuando la fatalidad desciende no tarda en aparecer la caída, y el escenario se cubre de sangre. Es lo que le pasó a Mauro Sari, de 47 años, residente de Savona, obrero especializado en pisos, quien condujo su motocarro (que hacía las veces de furgón de trabajo) hasta un área de parqueo para camiones de la autopista, a las afueras de Génova, en Vado Ligure, y allí, solo, se roció el cuerpo con gasolina y se encendió, solitaria antorcha humana, hasta morir por las quemaduras, un extraño gesto precisamente por ser solitario. Lo vio un conductor de camión que llegaba y dio la alarma, pero no hubo nada qué hacer. Todo suicidio es también un mensaje, pero, ¿por qué elegir una forma de suprimirse que tradicionalmente es considerada 
un gesto de protesta, y que por lo mismo se lleva a cabo en medio de una multitud?

El pasado mes de febrero (tres meses antes de inmolarse), Sari fue con su motocarro hasta San Ilario a la villa de Beppe Grillo, el político "anti sistema" italiano, y se estacionó al frente pidiendo ayuda. Hay una foto de él recostado contra su furgón, en el que puede leerse una pancarta que dice, "Gracias, Beppe". Fue a pedirle ayuda y así lo dijo ante la cámara de un noticiero que estaba por casualidad en el lugar, esperando declaraciones del cómico y político. "Voté por Grillo y espero no haberme equivocado, vine para que me diera un consejo, solo eso, nada más que eso". Sari se presentó diciendo: "Soy un obrero artesano con muchos problemas para mantener a flote mi trabajo por el exceso de burocracia. Llegué a un punto en que no puedo más".

Ese día Beppe Grillo lo recibió y habló con él. En la charla estuvo también otro micro empresario, Giuseppe Piscitello, que parecía en peor situación que Sari, pues no tenía ningún trabajo desde hacía un año y los bancos ya estaban a punto de quitarle la casa. Al parecer durante esa charla fue Piscitello quien obtuvo la mayoría de los consejos de Gri1lo, y Sari estuvo más bien silencioso.

Tras saber del suicidio de Sari, Beppe Grillo dijo lo siguiente: "Me siento partícipe del dolor y en cierto modo también responsable. Vino a mí desesperado, me reuní con él un par de veces, pero nunca pensé que llegara a hacer lo que hizo. Se trata de personas que nadie escucha, son invisibles y no tienen voz. Llegan a mí buscando alguna esperanza y nosotros tratamos de hacer algo, pero no siempre lo logramos".

Quienes lo conocieron dicen que era un hombre distante y que estaba atravesando una profunda depresión. La policía analizó su teléfono celular y encontró ese mismo día mensajes de apoyo de su esposa. Tras el suicidio de Sari uno de los sindicatos de empresarios abrió una línea de teléfono 24 horas para dar apoyo psicológico y consejo a quienes están desesperados. Sari no es el primer micro o pequeño empresario que se suicida, pero su extraño gesto de prenderse fuego en un solitario parking de autopista encendió las alarmas.

El año pasado, por esta época, el novelista italiano Giancarlo De Cataldo escribió lo siguiente: "Italia está viviendo una epidemia de suicidios. Es la crisis, dicen todos. Y todos echan la culpa a otros. Instinto de fuga. Pero si, como parece, estamos inmersos en el corazón de 
una crisis que golpea a todo Occidente (o buena parte de este) la culpa amenaza con ser de todos. Y por lo tanto, de nadie". Cuando De Cataldo escribió esto se habían contabilizado 290 suicidios, de los cuales 32 fueron pequeños empresarios, lo que permite hablar de una crisis que involucra otras esferas.

Sigue diciendo De Cataldo en su texto: "El suicidio puede ser un testimonio, un instrumento de lucha política, la afirmación de un último momento de libertad: Jan Palach que se quema para protestar contra los tanques de guerra soviéticos, el bonzo que se convierte en antorcha humana por la libertad del Tíbet, o Jacopo Ruffini, que se suicida en la cárcel para no traicionar a sus compañeros. Son situaciones extremas que le dan al suicidio un sentido trascendente, casi místico. En culturas diferentes a la nuestra el suicidio tiene el valor de ser una salida del escenario consciente y meditada. Un ritual que se puede calificar como acto de honor: la entrega a la memoria futura de una imagen excelsa de individuo capaz de una decisión radical $\mathrm{y}$, al mismo tiempo, que refuerza a la comunidad. Porque es una decisión compartida y, por lo tanto, que no se opone a la comunidad. Pero Italia pertenece a una cultura diferente. $\mathrm{O}$ al menos así se suele decir. Italia es un país católico. Y la Iglesia católica no admite el suicidio. Es más, lo condena. Como acto contra Dios y contra la comunidad. Una cadena de suicidios supone la alteridad radical con respecto a lo que somos, a lo que es nuestra cultura. Y desencadena interrogantes de gran profundidad: ¿somos aún un país católico? ¿A qué cultura debemos imputarle esta cadena de suicidios?".

Como dice De Cataldo, el suicidio es una nueva cultura. Y en el caso del empresario, un grito de ayuda y de desesperanza. Ese hombre que tiene una treintena de empleados, que ve que su empresa sigue teniendo pedidos pero no puede cumplirlos porque el banco no le da crédito para comprar materia prima, y así pasa el tiempo y cuando se da cuenta ya debe dos meses, tres meses de salario a sus empleados, que son su familia y lo miran con ojos secos. La oficina se convierte en una tortura. El sentimiento de culpa, la sensación de derrota, la pérdida del nivel de consumo, el temor a la imagen social. Ya me lo dijo Angelino el comunista. "Los bancos ganan más y por eso prefieren invertir en bonos que prestar la plata a quienes la trabajan", y por eso "les conviene la crisis". 
En este primer semestre de 2013 hubo un aumento del 10 al 15\% en los suicidios con respecto al año pasado. Pero no todos son de micro empresarios, como Sari. Hace un par de semanas, en la zona Boccea de Roma — barrio de clase media y media baja - un hombre de 53 años levantó también un pequeño tanque de metal y se roció con gasolina. Encendió su Zippo y se dio fuego. Un transeúnte lo vio cuando ya era una bola ardiente en llamas y le dio ayuda, llamó a la policía y a primeros auxilios. Entre varios lograron apagarlo usando abrigos, incluso un par de manteles de restaurante. El hombre no murió, pero quedó suspendido entre la vida y la muerte. Entonces se supo que desde el 1 de abril había perdido su trabajo como limpiador en el hotel Hilton de Roma. Una vecina del barrio que lo vio arder dio un testimonio sobrecogedor: "Vi las llamas, pero él no gritaba, no decía una sola palabra. Estaba ahí, quieto, con la mirada fija en el vacío".

Hace pocas semanas hubo otro hecho en Palermo (Sicilia) ligado tangencialmente a la crisis: en este caso se trató de un policía de 39 años que gustaba de hacer inversiones en Bolsa, pero la Bolsa tuvo una caída y el agente del orden, que soñaba con aumentar el capital de su familia, lo perdió todo, incluida su casa, en uno de los innumerables "lunes negros" de la economía italiana. Se llamaba Iván Irrera y acabó pegándose un tiro en la boca con el arma de servicio. Pero antes de hacerlo le disparó también a su hijo de siete años y dejó una macabra nota con una cita de la Biblia que dice: "Quien comete un error paga con su vida y la de su hijo". Le sobreviven su esposa y otra hija menor.

\section{V.}

Una sociedad como la italiana, tan enamorada del éxito, tiene un muy bajo umbral de aceptación del fracaso. En el 2010, ante la evidencia del desempleo juvenil, Berlusconi dijo: "Lo que deben hacer las desempleadas es casarse con hombres ricos, como yo". Muchas italianas siguieron su consejo: se acostaron con él o con sus amigos y obtuvieron trabajos en la televisión pública, otras fueron elegidas en sus listas electorales, como la guapísima Nicole Minetti, higienista dental y amante de Berlusconi, Consejera Regional en Lombardía por el Partido de la Libertad (PDL); otras llegaron incluso a su gabinete, como la ex modelo Mara Carfagna, a la que se le interceptó una conversación por 
celular con otra ministra en que le "explicaba" cómo se le debe hacer sexo oral a Berlusconi, y otras, simplemente, recibieron remuneraciones económicas por cada prestación.

La cultura del dinero y la facilidad, sin ningún escrúpulo ya no digamos moral sino incluso legal, imperó en Italia en los últimos 20 años, pero al llegar la crisis se acentuó, pues todo el mundo quiso salir desesperadamente a venderse, a seguir el modelo impuesto por el gran millonario y "macho alfa" de la nación.

En este orden de ideas no debe sorprender el enorme éxito de nuevos conceptos en Italia como el "Business Artist", un término que identifica a quien vive siguiendo el estilo de vida que ama, realizando, digamos, sus sueños y grandes pasiones, y obtiene una muy buena remuneración por hacerlo. Un ejemplo de esto son los libros de Alfio Bardolla, que se define a sí mismo en la contratapa de sus libros como "financial coach", "autor de bestsellers" y "empresario millonario", junto a Lorenzo Ait, quien es más o menos lo mismo. Su más exitoso libro se titula Millonario en 2 años y 7 meses, y es un compendio de experiencias y consejos para sacar adelante compañías pequeñas, incluso aquellas de una sola persona. A este libro, con más de 100.000 copias vendidas, le siguió Business Revolution, donde los consejos se dirigen de nuevo a los pequeños pero prometiéndoles directivas que les ayudarán en el rendimiento de modo que puedan tener "más tiempo libre y más dinero". Una especie de manual de autoayuda para empresarios.

En consonancia con la psicología italiana, estos exitosos autores no hablan de crear una empresa y llevarla adelante formando parte de la economía del país, creando industria y siendo un elemento propulsor dentro de la maquinaria social, sino que van directamente a la síntesis: conviértase en millonario. Y punto. Como si les dijeran a los lectores: "Mira, sabemos que eso es lo que estás pensando y lo único que te interesa, así que no le demos más rodeos y vamos al grano". Cuando las aguas se enrarecen y la economía es débil, este tipo de profetas suele obtener grandes beneficios, pues sus libros, más que teorías o modelos de pensamiento, presentan una especie de cartilla en la que se van sucediendo listas de cosas útiles "que todo empresario exitoso debe saber", mezclado con consejos sobre la psicología y el modo correcto de aproximarse a los problemas y retos, siempre con una sonrisa, y con la convicción de que "una crisis, en el fondo, es una excelente oportunidad 
para innovar". Y es así que centenares de miles de jóvenes, que en el fondo son el objetivo ("target") de este tipo de libros, andan por la calle repitiendo en la mente: misión empresarial, visión, capacidad de formar equipo, regularización de los procesos, leadership, gestión basada en resultados... ¿Qué porcentaje de lectores de estos libros de autoayuda empresarial llega a aplicar lo que aprende y obtiene mejoras y réditos? Me atrevería a decir que la posibilidad es igual a cero.

Así como las épocas de crisis traen bonanza para los profetas y refundadores del mundo, los que el poeta Jorge Zalamea llamó "los pregoneros de milagrerías y los loteadores de paraísos y nirvanas", también abren las puertas a uno de los grandes mercados y es el que podemos denominar el de "la posibilidad". Yo te vendo la posibilidad de ser exitoso, millonario, famoso. Ven a mí y muy pronto verás los resultados. El mercado de la posibilidad es también el de las loterías, que en Italia vuela por los cielos y que, eso sí, es en parte un monopolio del Estado, pues es el mejor negocio. Desde que empezó oficialmente la crisis, en el 2008, esta versión inmediata del mercado de la posibilidad se convirtió en el mejor negocio de Italia, llegándose a cifras estratosféricas: en el 2012, los italianos se jugaron 38,4 mil millones de euros en las máquinas y video loterías, más otros 9 mil millones en loterías del Estado, es decir, un gasto per cápita de alrededor de 1.500 euros anuales por italiano, para una suma que podría ser equivalente al monto del rescate que la Unión Europea tiene previsto para los bancos de España (entre 40 y 80 mil millones de euros).

$\mathrm{Y}$ en efecto, en todos los bares de Italia la gente, casi religiosamente, apuesta al Loto y compra papeletas de "raspe y gane" con una facilidad pasmosa, a pesar de que no son nada baratos: la mayoría cuesta entre 5 y 10 euros, y se pueden obtener con ellos ganancias máximas entre el medio millón y el millón de euros. Las loterías del Estado suelen tener un promedio de 15 a 20 millones de euros de premios, ipero juega tres veces a la semana! Esto obliga al jugador a gastar más. Basta mirar la papelera de los bares repleta de estos juegos ya usados para ver la enormidad de ese gasto. Es el mercado de lo posible que, en el fondo, es el mismo de los sueños. "Todos los ganadores de la lotería tienen algo en común, y es haber comprado un boleto", dice una vieja propaganda, para rematar: "Usted puede ser el próximo". 


\section{VI.}

Hay un elemento que aún no he mencionado y que dificulta la homologación de Italia, a nivel de impuestos y oportunidades, a las demás economías europeas, y es la economía ilegal. En otras palabras: la mafia. Según algunos datos confiables, cerca del 50\% de la economía del país es ilegal, e incluso cuando no está en manos de las organizaciones mafiosas, la economía se adhiere a esa cultura informal tan difícil de erradicar del país que es la compra y venta en negro, el horror metafísico al pago de impuestos alimentado por la incredulidad en la clase política, a la que el italiano promedio considera abusiva y corrupta. De ahí las dificultades de un gobierno interino como el de Monti en aplicar sus políticas de rigor y austeridad, que son la única receta que los economistas conocen para paliar estas crisis y que al parecer, visto el resultado, no son un remedio muy eficaz.

¿Qué hacer, entonces? Nadie lo sabe, todos se hacen la misma pregunta. Se supone que el futuro es el reino de la juventud, pero con un desempleo joven del $39 \%$ y con al menos un $11 \%$ de estos que ya ni siquiera buscan donde colocarse, por creer que pierden el tiempo, la cosa se pone aún más difícil. Tal vez Angelino, el viejo comunista de Collelungo, tenga razón: "Hay que hacer una cura de pobreza", y esperar que la vieja Italia, que según su constitución es una "República fundada sobre el trabajo", vuelva a salir a flote por la fuerza de su historia y de su talento individual. 